\title{
Pós-fácil - 0 pragmatismo utópico do comportamental-grupal de Oiticica
}

\author{
Post-Easy - The Utopic Pragmatism \\ of Oiticica's Behavioral-Groupal
}

\author{
Post-fácil - El pragmatismo utópico \\ del conductual-grupal de Oiticica
}

Luiz Guilherme Vergara*

Universidade Federal Fluminense, Brasil

https://doi.org/10.22409/poiesis.v20i34.39907

RESUMO: É diante dos colapsos de estruturas sociais e instituições públicas que se redobra a importância dos sentidos de futuro, das mudanças porvir antecipadas nos textos de Hélio Oiticica, The Senses Pointing Toward a New Transformation $^{1}$ e Subterranean Tropicália Projects ${ }^{2}$ (NY, 1971). Ao mesmo tempo que se reconhece a atualidade de uma utopia negativa da dissolução da obra objeto, esta abordagem ressalta o devir comportamental-grupal anarquista como mundoescola-floresta nas visões antecipadoras de Oiticica como pragmatismo utópico (a partir de William James). Complementa-se esta abordagem com o que Etiénne Souriau define como "projeto-trajeto", o "inacabamento existencial", da condição de "forma espiritual", ainda em "esboço" entre o texto e o PN15 Auto-Performance Penetrable (ambos inéditos), do que não ainda foi instituído, como cuidados expandidos para os próprios sentidos de mudança ética na virada do foco esteticista objetal para o comportamental-grupal.

PALAVRAS-CHAVE: Hélio Oiticica; comportamental-grupal; pragmatismo utópico

\footnotetext{
* Luiz Guilherme Vergara é professor associado do Departamento de Arte e do Programa de Pós-Graduação em Estudos Contemporâneos das Artes da UFF. É cofundador do Instituto MESA e coeditor da Revista MESA. E-mail: luizguivergara@gmail.com. Orcid: https://orcid.org/0000-0002-5311-5181
} 
ABSTRACT: In the face of the collapse of social structures and public institutions, the importance of the "senses" of the future and of anticipatory change in the texts of Hélio Oiticica, The Senses Pointing to New Transformation and Subterranean Tropicalia Projects (NY, 1971) become increasingly important. All the while recognizing the actuality of a negative utopia in the dissolution of the object/work, this article draws on William James to nevertheless underscore a utopian pragmatism in Oiticica's anticipatory vision of an anarchist group-behavioral becoming as a school-forest-world. This approach is further complemented by what Etiénne Souriau defines as "path project", the "existential unfinement" of the condition of "spiritual form", still in "outline" between the text and the PN15 Self-Performance Penetrable (both unpublished), from what has not yet been instituted, as expanded care for one's own senses of ethical change in the shift from the objective aestheticist focus to the group behavioral one.

KEYWORDS: Hélio Oiticica; behavioral-groupal; utopic pragmatism

RESUMEN: Frente a los colapsos de las estructuras sociales y las instituciones públicas, la importancia de los sentidos del futuro, de los cambios anticipados en los textos de Hélio Oiticica, Los sentidos apuntando a una nueva transformación y los Proyectos Tropicalia Subterráneos (NY, 1971). Si bien reconoce la actualidad de una utopía negativa de la disolución del trabajo objeto, este enfoque subraya el comportamiento anarquista grupal como un mundo forestal escolar en los puntos de vista anticipatorios de Oiticica como pragmatismo utópico (de William James). Este enfoque se complementa con lo que Etiénne Souriau define como "proyecto de ruta", el" desenfreno existencial "de la condición de" forma espiritual ", todavía en" esquema "entre el texto y el PN15 Auto-Performance Penetrable (ambos inéditos), de lo que aún no se ha instituido, como una atención ampliada a los propios sentidos de cambio ético en el cambio del enfoque estético al enfoque conductual grupal.

PALABRAS CLAVE: Hélio Oiticica; conductual-grupal; pragmatismo utópico

Citação recomendada:

VERGARA, Luiz Guilherme. Pós-fácil - O pragmatismo utópico do comportamental-grupal de Oiticica. Poiésis, Niterói, v. 20, n. 34, p. 261-286, jul./dez. 2019.

[https://doi.org/10.22409/poiesis.v20i34.39907]

Luiz Guilherme Vergara. Pós-fácil - O pragmatismo utópico do comportamental-grupal de Oiticica. 


\section{Pós-fácil - 0 pragmatismo utópico do comportamental-grupal de Oiticica}

Parte I

Primeiro giro: Pragmatismo utópico dos sentidos de mundo-escola-floresta no labirinto espiral PN15

Aquilo que fazia era como um espetáculo. Mas não havia outra possibilidade. Entre a ação e o espetáculo, ele não tinha escolha. Tinha apenas uma escolha: dar um espetáculo ou não fazer nada. Existem situações em que o homem é condenado a dar um espetáculo... é 0 combate de um grupo de teatro que enfrenta um exército. ${ }^{3}$ (KUNDERA, 2017, p. 287)
É diante dos colapsos de estruturas sociais e instituições públicas que se redobra a importância dos sentidos de futuro, das mudanças porvir antecipadas nos textos de Hélio Oiticica, The Senses Pointing Toward a New Transformation (1969) e Subterranean Tropicália Projects (NY, 1971). Os sentidos do comportamental- grupal são abordados como bases éticas para o devir mundoescola-floresta que se traduz como pragmatismo utópico (a partir de William James) presentes em texto, obras, proposições e 
vida de Oiticica como um único "programaobra in progress"4. (OITICICA, 1979) O que também é adotado por Etiénne Souriau como "projeto-trajeto", o "inacabamento existencial" de uma "obra por ser feita", em sua condição de "forma espiritual", ainda em "esboço" tal como a incorporação escrita e percurso entre o texto e o PN15 AutoPerformance Penetrable (ambos inéditos), do que ainda não foi instituído.

O pragmatismo da ação com o qual Lapoujade (2017, p. 88) aborda William James complementa a radicalidade crítica dos sentidos do comportamental implícitos no resgate de vínculo e confiança no mundo e se desloca da descrença para o devir-agir no mundo em "inacabamento existencial".

\section{[...] Se a confiança faltar, as percepções não serão mais suficientes para nos fazer acreditar neste mun- do, para fazê-lo significar. A ligação que temos com o mundo é, portanto, extremamente frágil... Tudo se desfaz... Qualquer ação se torna impossível. A confi- ança não é a condição do "sucesso; ela é, antes de mais nada, vital". (LAPOUJADE, 2017, p. 88)}

Abordam-se nesta releitura os cuidados expandidos para os próprios sentidos de mudança no foco esteticista objetal para o comportamental-grupal como devires de um programa-obra de arte para/com o mundo como escola-floresta. A exigência da ação como pragmatismo utópico das práticas de situamentos geopoéticos, de cocriação comportamental entre artistas e destinatários desconhecidos abrem caminhos contemporâneos para as especulações éticas-estéticas dos sentidos de mudança ainda por ser feito para uma escola de arte em seu devir experimental - ambiental - floresta.

Os sentidos apontando para novas transformações que não deixam de ser uma chamada para o pragmatismo utópico da açãopraxis transmodal de produzir novas conexões entre diferentes modos de existência e devir circular, cambalhotas para novas ontologias - epistêmicas, da "linguagem-infância". (PELBART, 2008) O que também confirma a dobradura entre ação criadora transmodal e "confiança" como Lapoujade cita William James: "As novas ideias precedem os hábitos derivados dela... Agimos quando temos confiança nos nossos motivos, nas nossas capacidades e no devir do mundo que vai realizá-Ios". (LAPOUJADE, 2017, p. 86)

Em um primeiro momento do texto "Os sentidos apontando para novas transforma-

Luiz Guilherme Vergara. Pós-fácil - O pragmatismo utópico do comportamental-grupal de Oiticica. 
ções", Oiticica se inspira na fenomenologia de Merleau-Ponty, em especial nas "estruturas de comportamento" como investimento no primado da percepção e dos sentidos, a "simbólica do corpo" na produção de significação, tal como centralidade e coração da obra no "aparecimento do suprassensorial" na arte. Oiticica aponta com MerleauPonty para um reposicionamento sensorial do corpo no mundo, como pertencimento e interdependência, como o "coração" de todos os movimentos à nossa volta: "O próprio corpo está no mundo assim como o coração no organismo; ele mantém o espetáculo visível continuamente em vida, animao e alimenta-o interiormente, forma com ele um sistema." (PONTY, 1999, p. 280) A partir do reconhecimento deste corpo como parte estruturante da extensão e do situamento do sujeito em estado de invenção de si e da arte, Oiticica investe no campo comportamental, na participação movente do espectador como dimensão infinita, macromicro existencial e cósmica.

Pode-se rever uma década a partir desse texto de Oiticica, apontando o seu desenvolvimento-percurso existencial, estético e geopoético para a potência crescente de proposições - propor-propor - sistemas supras- sensoriais - dirigidos ao corpo participante do espectador em relação com os outros, agora como coração e mente coletiva - pulsação celular - na obra-organismo ou sistema ambiental do acontecer solidário da arte. Acrescenta-se o que Therry de Duve define como "intuição-sintoma" nesta abordagem prospectiva e cartográfica da visão de Oiticica para o contemporâneo sobre o seu próprio desenvolvimento a partir da "desintegração de conceitos formais", revelando a emergência de uma "utopia negativa" (CARRASCO; REBECO, 2006), distopias, em estruturas e células penetráveis para experiências coletivas de corpos multissensoriais em auto-performance penetrable. Fredy Parra Carrasco aponta para a utopia negativa como necessidade de instrumentos e agentes críticos que "denunciam a ordem existente". (CARRASCO; REBECO, 2006, p. 26)

Enquanto Oiticica adotava as viradas fenomenológicas existenciais como artista propositor de ambientes de convivência, as dissoluções de fronteiras entre sujeito-objeto, espectador e cocriador tornavam-se constructos ambientais para imersões e acolhimentos de experiência e performances espontâneas em áreas urbanas. Seu interesse se deslocava pelo alinhamento entre a descoberta, sin- 
toma e intuição de imaginários instituintes do ambiental e da antiarte dos anos 1960, já em meio a ditadura militar. Com toda uma geração, as vanguardas lutavam através de utopias negativas ou distopias apontando para a desintegração do objeto, para as desformas, para os lugares de convivências prospectivos de relações interpessoais de corpos-coletivos geopoéticos. Igualmente, Oiticica nesse texto também está apontando para as transformações dos sentidos e os sentidos da transformação na obra da Lygia Clark.

[...] quando Lygia Clark, por exemplo, propõe sua experiência de "a nostalgia do corpo", ela está propondo, através de simples atos sensoriais, a possibilidade de uma consciência re-informada do corpo como algo vivo, como se descoberto pela primeira vez, assim propondo uma nova relação entre 0 autoconhecimento e o conhecimento dos outros. (OITICICA, 1969)

Anacronicamente, a utopia negativa da desobediência e des-forma epistêmica constitui o pragmatismo utópico da ação, das lutas e táticas de "cambalhotas" para o subterrâneo (underground) dos "inacabamentos existenciais" da revolução dos afetos e das estruturas formadoras de novos modos de comportamento, de viver, daí também apontando para outras ontologias.

\section{[...] as estruturas antigas das arte-formas, que fo- ram concebidas para serem estruturas totais condi- cionantes de comportamento das estruturas-totais, se dissolveram nessas evoluçōes e passaram a pro- por 0 inverso disto, que seria o comportamento de- finido como estrutura-total, gerando os elementos que não são estruturas de arte total (aberto-aberto), mas o fluxo vivo da experiência do destino humano. Esse processo é sem fim e nenhuma oferta de solu- ção rápida deve ser feita. É um processo dentro de um processo. (OITICICA, 1969)}

Estes instituintes utópicos e distópicos, que não deixam de ter ressonâncias com o pragmatismo de William James ou "inacabamento existencial" da obra em seu estado de esboço - "projeto-trajeto" - da "obra por ser feita", segundo Etiénne Souriau, que apontando para "o fluxo vivo da experiência do destino humano", podem ser atualizados como emergências de uma curva espiral de um "processo é sem fim... processo dentro de um processo". Oiticica coloca de forma bem clara sua "metacrítica" à própria fragilidade do sentido de participação: "é inútil ter "participação" ou "proposições", caso não estejam pautadas por

Luiz Guilherme Vergara. Pós-fácil - O pragmatismo utópico do comportamental-grupal de Oiticica. 
uma mudança completa na relação-objetal; o mesmo com o que poderia ser chamado de "participação sensorial". (OITICICA, 1969)

O adensamento crítico deste texto de Oiticica alimenta uma prospecção cartográfica de projeto-trajeto, de antecipação de futuros (BLOCH, 2005), "obra a ser feita" (SOURIAU), embasado em suas próprias experiências (incluindo, certamente, Lygia Clark), tal que

construir novas possibilidades de caminhar através delugares (... eu proponho muito mais um "ambiente aberto vivo" do que qualquer coisa que seja objetal, que poderia ainda manter velhas ideias formais).

\section{As experiências comunais internas são as mais} complexas e fascinantes: a ideia de desenvolver relações-experimentos grupais-expansivos pode criar células expansivas para futuros experimentos; eles podem ser centros, pequenos centros com certeza, de experiências-vivas condensadas e fechadas, onde a demanda por um novo tipo de relacionamento social seria essencial... (OITICICA, 1969)

Nesta mesma abordagem aproximam-se os "atos de intenções" antecipatórios de Ernst Bloch (2005) e as "complexidades inquie- tantes" de Souriau com os elos do "projetotrajeto" entre o texto The Senses Pointing Toward a New Transformation (Oiticica, 1969) e o esboço-maquete para Subterranean Tropicália - Série Newyorkaises, PN15 (1971), integrantes dos giros do labirinto espiral como devires escola-floresta. A própria planta-maquete do PN15 (Auto-Performance Penetrable) já é um modelo de futuro de 40 anos atrás ainda em "esboço" pela distopia da total dissolução - "dissolução objetal" - apontando para o "mundo do comportamento[al]". A estrutura viva em "esboço" projetada por Oiticica para uma obra trajeto espiral dentro de um círculo já é, em si, uma visão geopoética para uma escola devir floresta unindo uma esculturacaminho com um corpo-simbólico em trânsito na aderência in-corporada a um mundo - campo circular, aldeia, oca-floresta. No esboço do programa deste penetrável estavam previstas áreas para auto-performances (definida pelo artista como espaço para performances espontâneas sem direção pré-organizada; área para plantas; diferentes áreas de proposições e performances; plataforma com equipamentos eletrônicos e outra para projeção. É possível reconhecer no PN15 um pragmatismo utópico da obra cujo sentido é ação como campo de convi- 
vência, ou seja, um outro modo de existência "não-ainda-concluído". (BLOCH, 2005)

Ainda aqui ressalte-se no texto de Oiticica a "crença e confiança" (LAPOUJADE, 2017) no papel da arte em gerar vínculos interpessoais com o mundo, tal como abordado no "pragmatismo-pluralismo" de William James, como modo-método de ação direta no mundo em "esboço", como responsabilidade de agir para o devir de novos horizontes humanos de compartilhamentos, sendo parte do "inacabamento existencial" como "obra por ser feita" da "forma-espiritual" de

Propõe-se uma conexão geopoética ou, ainda, cartográfica entre o penetrável circularespiral $P N 15$, os giros de diferentes triângulos áureos formando também uma espiral infinita em todas as direções macro-micro e o que se complementa com a figura do disco utilizado por Mário Pedrosa (1979) para o desenvolvimento de sua tese proposta para a Natureza Afetiva da Forma. Colocase em jogo cartográfico a escrita em espiral como caminhante para o "meditar-andar" (BRAGA, 2013, p. 250), apontando para a interdependência fenomenológica existencial entre corpo e mundo também amplian-

do a gestalt da alternância figura-fundo no diagrama do círculo como estruturas de percepção em movimento - e moventes para um leitor e visão em movimento. Em todas essas visualizações em esboço têm-se o círculo como imagem e como verbo. Neste giro espiral também se retomam as anotações e especulações filosóficas livres de Oiticica de 1959 como um devir que se resgata na maquete do PN15 como estrutura programa gênese de uma geometria e geografia, mais geopoética do estático, imóvel e movente.

\section{[...] as formas originárias vêm do incomensurável infinito e geram todas as outras. São estáticas, pois as estáticas possuem mais força. São simétricas e transcendem a tudo que se pode imaginar. Concre- tamente 0 círculo se enquadra nestes princípios. É forma transcendente por excelência; e a enuncia- dora do mais profunda silêncio; e a síntese do pró- prio Cosmos: por isso, possui um extraordinário vi- gor. (OITICICA, 1986, p. 15)}

O que estaria também antecipando suas proposições ligadas ao "meditar-andar", como bem explora Paula Braga (2013, p. 250). O PN15 estaria nesta dimensão infinita dos sentidos de experiência de liminalidade metafísica entre transe e forma trans-

Luiz Guilherme Vergara. Pós-fácil - O pragmatismo utópico do comportamental-grupal de Oiticica. 
cendente - esboço e maquete, projetotrajeto, de uma luta do artista pelo campo aberto desde o "Programa Ambiental", o "Barracão" ao "Mundo Abrigo" que se realizaria a partir de 1973 como "Delirium Ambulatorium" e "Dreamtime" e "Não tenho lugar no mundo".

\section{- o mundo me parece pequeno e feio - ondeestá 0 sonho do novo mundo? do $3^{\circ}, 4^{\circ}, 5^{\circ}$ ou a obsessão in- fantil? - o mundo é maior do que se pensa, mais per- dido, e 2/3 de mar, animal e só, vazio de humano. (OITICICA, 1986, p. 123)}

O que pode ainda caber nos sentidos de mudanças dentro do círculo - espiral geopoético e cosmopoético de devires no PN15 poderia ser também um mundo-escola - de sonhos diurnos como Ernst Bloch definiria a função utópica da arte ou daydreams de Mircea Eliade. Manter-se na escrita espiral é também parte do pragmatismo utópico de um "inacabamento existencial" (SOURIAU) que Oiticica declara em Londres (1969), "mas parece que o infinito de ruas e casas se fecha - procuro o crelazer: os planos, e parece que o começo e recomeço não terminam e são o sentido do que não existe e se procura erguer". (OITICICA, 1969)
O caminhar passa a ser totalmente meditar, seja em Londres ou no Rio de Janeiro, para Oiticica, muito inspirado por Yoko Ono. (BRAGA, 2013, p. 253) Mas também remete a mais um fio solto de presenças intuitivas (não-ainda-publicadas) das práticas meditativas do seu avô José Oiticica que também caminhava em silêncio por uma hora, sem cumprimentar ninguém, em preparação para as suas aulas na Rosa Cruz em Niterói. 5

Vale citar o epílogo da Mário Pedrosa (1979) com uma referência a uma "revolução espiritual" que se emaranha entre anarquismos e pragmatismos utópicos das viradas e devires para um mundo-escolafloresta no qual se foca esta abordagem. Pedrosa faz suas as palavras de MoholyNagy, como conclusões para a "Natureza Afetiva" ou, talvez melhor, destino-devir afetivo da dissolução da forma em "movimento de novas maneiras de viver":

Felizmente, é uma qualidade inesperada do movimento de arte moderna o fato de que algumas facetas possuam relações ocultas com a vida prática. (Com efeito, pode-se dizer que todo o esforço criador de hoje é parte de um programa de preparação indireta e gigantesca para remodelar, através da 
visão em movimento, os modos de percepção e de sentir, e para conduzir a novas maneiras de viver). (PEDROSA, 1979, p. 145)

\section{Parte II}

Cartografia de uma escrita geopoética encarnada - Do inacabamento existencial à forma espiritual

A meta-estrutura editorial deste dossiê igualmente projeta o leitor (através de emaranhamentos dos diferentes artigos e entrevistas) em movimento neste projetotrajeto labirinto espiral compondo o pluralismo "multifocal" cartográfico de viradas moventes para os sentidos, onde natureza, origem e destino apontam para o abrigo afetivo da arte como "forma espiritual" na estruturação de campos e situações coletivas de interrogações e projeções. O conceito de uma leitura-caminhante fenomenológica tanto remete ao grande labirinto de "cambalhotas no cosmos" 6 , expresso no lance final III das especulações estéticas de Mário Pedrosa (1986, p. 136), quanto à "espessura do presente" cruzadas por colapsos sociais e ambientais e a condição multifocal das práticas e pesquisas no campo artístico contemporâneo.
A curva circular-espiral do $P N 15$, que aspira para o labirinto espiral de triângulos em rotação como plataforma de base metapoética e geopoética, atualiza também a transtemporalidade das preocupações e especulações filosóficas de William James e Etiénne Souriau a Mário Pedrosa em 1967. O que equivale ao que Pedrosa aponta em resposta à crise do "homem, objeto de objeto de si mesmo", projetava através da metáfora da "cambalhota no cosmos sobre si mesmo, seu destino... Isto é, que somos nós mesmos, ainda e sempre". (AMARAL,1986, p. 139) Enquanto as falências do antropocentrismo e do articentrismo ${ }^{7}$ (ACHA, 1979) são agravadas, as inquietações e atos de intenções intuitivos colocam em jogo o sentido das transformações e mudanças no foco da produção artística contra o "antropoceno/capitaloceno".

O que não deixa de ser uma "cambalhota no cosmos" que se dá também como giro epistêmico-ontológico para o acolhimento transmodal (Souriau) de outros modos de existência, como novos estados inaugurais - de "esboço", infância e pré-ontológico. Atualizam-se as especulações e inquietações de Pedrosa: "o saber explícito esclarece, sem dúvida, a compreensão pré-onto-

Luiz Guilherme Vergara. Pós-fácil - O pragmatismo utópico do comportamental-grupal de Oiticica. 
lógica do ser, mas o diabo é que pode implicar o obscurecimento do próprio ser transmudado em objeto 'pré-ontológico'". (AMARAL, 1986, p. 138)

As dobraduras contínuas entre estado de infância inaugural "pré-ontológica" e a descoberta-invenção (OITICICA) de desobediências epistêmicas espelham os giros de Oiticica entre linguagem e metalinguagem, desde os exercícios da abstração geométrica junto a Ivan Serpa no Grupo Frente ao devir ambiental geopoético dos metaesquemas. As seguidas dissoluções do objetal são parte da evolução para as estruturas vivas da gênese comportamental (anarquista) dos penetráveis para as "auto-performances". O que se reconhece no desenvolvimento de seu próprio trabalho, desde os penetráveis, para a "desintegração de conceitos formais" (development of the desintegration of formal concepts)" 18 vale também para as novas ordens de mundo porvir - de relações entre diferentes modos de existência, incluindo o humano-inumano; os fenômenos e os outros imaginários tangíveis e intangíveis.

No entanto, ressalta-se o sentido de incorporação de Oiticica atravessando toda a gênese da escrita-leitura do artista como passagem geopoética pela fenomenologia existencial das relações entre delirium ambulatorium e escritas encarnadas de pragmáticas da ação existencial em suas obras (por ser feita), programa-obra in progress, em especial na circularidade espiral do PN15. Paula Braga ${ }^{9}$ aborda a curiosa recusa da publicação deste texto pela revista Studio International em 1969, justificada a partir de problemas, tais como, "as passagens intrincadas e de difícil interpretação para o leitor que não acompanhava os textos anteriores do artista, escritas com a liberdade de quem se apropriava livremente de conceitos filosóficos, criava neologismos e novas regras de pontuação, inserindo sinais gráficos no texto, como setas, para indicar o desaguar de uma sentença em outra." Porém, é exatamente neste aspecto gráfico, linguístico e semântico, com uso de setas, "traços de união", sinais, que se registra uma outra pista ainda por ser estudada sobre a singularidade da produção textual de Oiticica. Resgata-se nessa oportunidade uma outra história não publicada da memória da educação familiar anarquista de Hélio Oiticica através dos relatos de Vera Oiticica ${ }^{10}$ e o legado (intuitivo) de seu avô (anarquista), o educador José Oiticica. 
Os sentidos de devir podem ser tomados como gênese de uma série de novas "descobertas-invenções" como processos dentro de processos inacabados, como referências existenciais/espirituais que emergem como fios ainda soltos para maiores conexões por serem feitas.

O uso recorrente de setas, círculos e contornos demarcando sujeitos, verbos, predicados e objetos, traços de união, que formavam a gramática de José Oiticica (avô), interpenetraram subterraneamente a escrita-leitura do Hélio como cartografias sobrepostas ao texto para um leitor movente. Ainda pouco estudada, as conexões e vínculos com a gramática do avô, José Oiticica, que, além de anarquista e mestre rosacruz, era um grande estudioso da língua portuguesa, sendo autor-criador de uma gramática que sobrepunha a escrita com um vocabulário gráfico. Não se sabe ainda o quanto Oiticica expandiu conscientemente esta presença e influência de sua educação familiar para uma complexidade geopoética de sua produção crítica e literária que se expande ou transborda para suas obras e labirintos em delirium ambulatorium, da tropicália subterrânea para a metafísica e cosmos, e sempre retornando ao corpo- simbólico suprassensorial / crelazer / crecomportamental.

Apenas como uma pista para uma necessidade de aprofundamentos ainda por serem feitos sobre esta escrita in-corporada na experiência do corpo-caminhar e mundo, Oiticica aborda o sentido de "união" ao hífen de in-corporação, demonstrando uma unidade diferencial do uso gráfico e semântico do traço de união. "Nos Parangolés toda essa experiência passa a fazer parte integrante do corpo, ele nos diz: " é a total in-corporação. É a incorporação do corpo na obra e da obra no corpo... eu chamo in traço de união, corporação". ${ }^{11}$

Pode-se intuir ou apenas especular sobre o impacto desta educação anarquista familiar como gênese do inconsciente-consciente afetivo de descobertas-invenções, que inspiram os sentidos linguísticos e geopoéticos das in-corporações e apropriações da escrita encarnada em éticas sociais da obraprograma de devires para estruturas comportamentais.

Luiz Guilherme Vergara. Pós-fácil - O pragmatismo utópico do comportamental-grupal de Oiticica. 


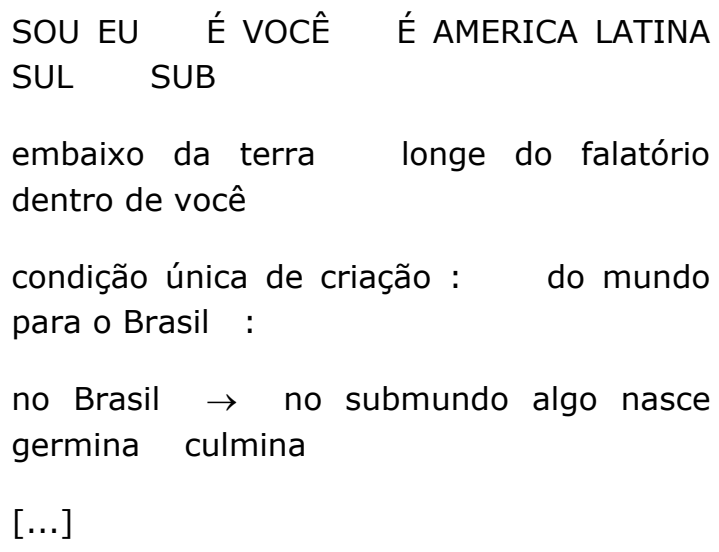

\section{Parte III}

\section{Projeto-Trajeto Espiral / Fenomenologia existencial da terra à terra}

São dez anos que se unem em uma única dobradura entre escrita para o Simpósio Touch Art (1969) e a série Subterranean Tropicália Projects, como parte deste mesmo projeto-trajeto de inquietações e indagações que aspiram ao grande labirinto do mundo em dissoluções, também da desintegração de conceitos formais até sua culminância no Contra-Bólide Devolver a terra à terra (1979), "ou seja, é a contra operação poética da q gerou o BÓLIDE". (PROJETO HÉLIO OITICICA, 1997, p. 202)

Cabe revisitar Etiénne Souriau ${ }^{12}$, um filósofo francês fora de moda, assim apresentado por Isabelle Stengers e Bruno Latour, colocando posições estéticas em contrafluxo com as abordagens dominadas por um modo de pensar monolítico que regia e rege os campos de produção de conhecimento. Como Lapoujade, Peter Pál Pelbart (2014, p. 250) cita Souriau pelo seu direcionamento para novos modos de existência em paralelo à condição de "inacabamento existencial de todas as coisas". Seja através da releitura de Stengers e Latour, ou ainda mais recente- 


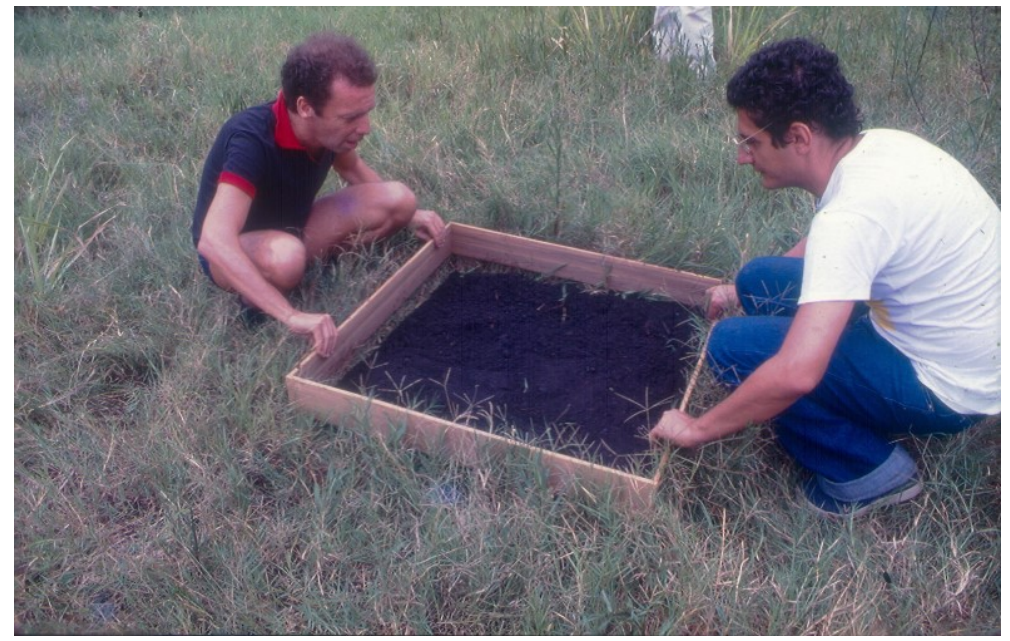

Fig. 1 - Hélio Oiticica com o Contra Bólide No 1 - Devolver a terra à terra, Rio de Janeiro, 1979.

(Foto: Andreas Valentin)

Luiz Guilherme Vergara. Pós-fácil - O pragmatismo utópico do comportamental-grupal de Oiticica. 
mente Peter Pál Pelbart, Souriau é revisto através do texto de Oiticica exatamente pelo anacronismo de suas posições e abordagens conceituais antecipadoras de posicionamentos estéticos e éticos extremamente presentes hoje. Vários pontos conceituais aproximam Oiticica a Souriau pelo viés do pragmatismo utópico de William James sobre o devir dos sentidos no projeto-trajeto de uma nova ordem de transformações "por serem feitas", como forma espiritual em devir planetário da terra à terra.

Para Souriau, o sentido de processo artístico em "Del modo de existencia de la obra por hacer" é indissociável da produção de uma "situação interrogante" que se desdobra sobre o próprio artista (e também para a sociedade) como indagação do seu sentido de criação e recepção: "Adivinhe ou você será devorado?" (SOURIAU, 2017) Os sentidos apontam e indagam para as diferentes mudanças, por novas ordens, que poderiam também ser colocadas em diálogo com as especulações de Etiénne Souriau quando trata da "obra por ser feita". O filósofo projeta a conceituação de "instauração" como desdobramentos de processos dentro de processos (OITICICA) indissociáveis do inacabamento existencial, dos riscos de falibili- dade, vulnerabilidade, em contraponto com sua compreensão de obra a ser feita como "forma espiritual".

\section{Todas cosas que evidentemente se pueden comen- tar a través de una comparación con el amor. Y, de hecho, si el poeta no amara ya un poco el poema antes de haberlo escrito, si todos los que piensan un mundo futuro por hacer nacer no encontraran en sus sueños al respecto algún presentimiento maravillado de la presencia llamada. (SOURIAU, 2017, p. 45)}

Os textos de Oiticica são marcados por essa fenomenologia da in-corporação entre escrita-consciência-espacialização tal como percurso entrelaçado do corpo, pensamento e produção de linguagem em movimento no mundo. Sem dúvida, deve ter sido muito difícil para o editor inglês acolher essa escrita encarnada entre cartografia e filosofia. Paula Braga menciona como Oiticica abordava Nietzsche, Bergson ou Marcuse, como uma apropriação do "que the servisse como impulso, e constituía, a partir daí, sua própria argumentação e elaboração de conceitos." Seguramente, se poderia abordar a escrita de Oiticica como fenomenológica onde literalmente ele encarna, in-corpora, o posicionamento ressaltado pela Paula Braga, como 
"Merleau-Ponty... na refutação da dicotomia entre consciência e mundo, e o estabelecimento do corpo como cerne da relação do sujeito com o mundo. Não é o intelecto que propiciará essa relação, e sim a percepção sensorial." Se esta era a dificuldade de aceitação do texto da parte do conselho editorial da Studio International, fica claro que a potência e consistência experimental entre produção artística, crítica e poiética existencial de Oiticica estavam exatamente nesta escrita fenomenológica encarnada na "descobertainvenção" de ser, e seu "inacabamento existencial" (SOURIAU) enquanto também produção de mundos, abrigos, labirintos penetráveis e espirais suprassensoriais.

Ressalte-se que o que Souriau aborda como "projeto-trajeto" pode ser apropriado para a maquete do $P N 15$ (1971), primeiramente pelo fato de ser inédito, como "esboço" ou devir. Sendo o único penetrável circular do artista, ele também territorializa o corpo-leitorsimbólico como movente interpenetrável em uma caminhada sempre em curva, igualmente em espiral, de fora para dentro, como uma célula ou átomo em direção ao núcleo, centro onde o espaço é compartimentado entre plantas com referência ao sentido ambiental, ou melhor, "floresta" - lugar de convivência - auto-performances (espontâneas). Ali, Oiticica previa também telas para projeções de filmes tal como uma intuição de futuro porvir de um mundo de novas tecnologias - tanto um laboratório de comportamento anarquista quanto floresta multissensorial. A obra é um programa e gênese ainda por ser feita como estrutura-processo vital-ambi-ental - "eu proponho muito mais um 'ambiente aberto vivo' do que qualquer coisa que seja objetal, que poderia ainda manter velhas ideias formais". (OITICICA, 1969)

O entrelaçamento entre projeto-trajeto como "obra por ser feita" constitui parte indissociável do "inacabamento existencial" (SOURIAU) se materializando como uma linguagem integral escrita para, e com, um corpo simbólico de experiência e significação. (OITICICA, 1969) Os sentidos apontam para o pragmatismo da dobradura entre origem e devir fenomenológico-existencial pela ação estruturante comportamental abrindo os estados de descoberta-invenção do artista para a "auto-performance" como um mundo-escola-floresta anarquista.

As percepções de futuro e de sonho, pressentimento e presença de Souriau de imediato remetem ao pragmatismo da função

Luiz Guilherme Vergara. Pós-fácil - O pragmatismo utópico do comportamental-grupal de Oiticica. 
utópica da arte de Ernst Bloch, que se realiza como agir de "sonhos diurnos". Ambos abordam sob diferentes ângulos o "inacabamento existencial", incluindo o próprio mundo.

Para Bloch, "pensar significa transpor. Contudo, até agora, o transpor ainda não encontrou o seu pensar mais preciso". O sentido de "futuro, front e novum" é colocado em questão por Bloch juntamente com o exercício humano do que é defendido por Marx como o que "representa a reviravolta na tomada de consciência do transpor o concreto". (BLOCH, 2005, p. 16) Deste estado de reviravolta inacabado, Bloch constrói sua cartografia de princípios esperança, desde o "ato de intencionar" em seu tom antecipatório. O antecipatório, tal como "função utópica da arte", define "o aindanão-consciente, o que-ainda-não-se-tornou, embora preencha o sentido de todos os seres humanos do horizonte de todo ser". (BLOCH, 2005, p. 16) Este horizonte é também o "florescente campo de interrogações" que Bloch vincula ao "sonhar para frente" de Lênin.

Formam-se aqui especulações e intuições antecipatórias sobre o legado de ideias de Oiticica para esse devir escola anarquista como floresta dos sentidos, tais como "metaesquemas" conceituais e éticos para transformações da arte-objeto em estruturas comportamentais multidirecionais. A dimensão infinita-existencial complementa o sentido de centralidade das ações no corpo-simbólico em trajeto, trânsito dentro de uma espiral de duas pontas de construção de experiências, na reversibilidade causal entre o macro e o micro. $O$ "que pode ser uma concentração 'multifocal' se torna importante como um meio para a assimilação comportamental: olfato-visão-paladar-audi-ção e tato se misturam e se tornam aquilo que Merleau-Ponty chamara de 'simbólica geral do corpo'". (OITICICA, 1969) De um lado, Oiticica expõe sua vontade construtiva de investir pelo anacronismo de uma utopia negativa da dissolução da arte, ou das referências à Teoria do Não-Objeto de Ferreira Gullar, na totalidade da experiência "para uma ideia de mundo humano-integral para a crença na ação comportamental". Por outro, também prenuncia, por sua intuição-sinergias-sintomas que pertencem a trajetória dos anos 1960, para o niilismo e distopias da contemporaneidade, "a dissolução da 'arte' nisto não é também uma 'dissolução objetal' (...) na manifestação da vida até onde for o alcance do infinito campo do comportamento humano". 
Neste campo de interrogações, como pensar o transpor o front do que os "sentidos estão apontando como novas transformações"? Para Bloch, "o que foi suplanta o que está por vir, a aglomeração das coisas havidas obstrui totalmente as categorias de futuro, front, novum". (BLOCH, 2005, p. 18), o que também foi defendido por William James em seu pragmatismo. Bloch coloca em questão o transpor "o mundo da repetição...; o "evento torna-se história; o conhecimento, rememoração; a festividade, comemoração do que já ocorreu." Continua Bloch: "pensar significa transpor", quando os sentidos exigem a dissolução dos estados de contemplação passiva, quando até mesmo o conhecimento se torna objetal para mentalidades idealistas, "pressupondo consequentemente um mundo feito, acabado, apreciado apenas de modo passivo. [...] Portanto, um futuro do tipo autêntico, aberto como processo, é inacessível e estranho a toda mera contemplação". (BLOCH, 2005, p. 18)

Aqui se tem uma verdadeira cambalhota para o que Oiticica vai conceituar como "comportament[al]", já apontando para o papel dos sentidos como base para uma nova transformação. Entre o pragmatismo utópico da vontade construtiva e o inaca- bamento existencial do programa vital do exercício experimental da liberdade, Oiticica estará sempre dedicado à síntese entre "descoberta-invenção" como binário que compõe a "forma espiritual" (SOURIAU) da "dimensão infinita"13 da arte no mundo humano-integral. Os sentidos de intuição e invenção vão apontando Oiticica para "uma estrutura criativa, oposta ao mundo objetal, como um 'modelo' de verdade sintética e não corrompida em si", o que não deixa de ser uma perspectiva pragmática de ética viva da arte como "obra a ser feita" ou como Souriau propõe como "instauração" da "forma espiritual" do acontecimento artístico e existencial com o devir do mundo.

A culminância entre vida, escrita-projetotrajeto de volta à vida segue a intuição e potência dos sentidos como descobertainvenção dos estados de criação do Oiticica. "O Contra-bólide revelaria a cada repetição desse programa-obra in progress o caráter de o caráter de concreção de obra-gênese $q$ comandou a invenção-descoberta do Bólide nos idos de 63: por isso, era o Bólide uma nova ordem de obra e não um simples $o b$ jeto ou escultura" (OITICICA, 1997, p. 202), apontando sempre para um anacronismo de dois aspectos utópicos - do 
pragmatismo da vontade construtiva, dimensão infinita e a utopia negativa, a distopia contínua da dissolução do foco objetal. A obra gesto de distopia radical - "devolver a terra à terra" (1979).

A "dissolução objetal" é acompanhada por derivas pelas cidades (BRAGA, 2013) que deram bases para a "ideia de comunidadescélulas ou de comunidades experimentais veio a mim em paralelo às amplamente divulgadas coletividades, tal como a construção de sítios coletivos ou lugares de habitar [...] lugares de habitar grupal, onde os experimentos não estariam vinculados à ideia de um 'experimento-show'". Entre o fascínio pelo "barracão" e uma fenomenologia existencial, o desvio do niilismo é contorcido por vários anacronismos críticos às tendências da época - "das experiências integrativas, que para mim ainda possuem conotações objetais estética". Para além dos penetráveis, desde o aparecimento do Suprassensorial em 1967, os sentidos de evolução e superação do objeto para o comprometimento com o comportamento já apontavam para as viradas existenciais do "Mundo Abrigo". São viradas contínuas conceituadas pelo artista em várias prospecções intuitivas em ressonâncias com a crise da arte e antiarte dos anos 1960, invocando conjugações geopoéticas e cosmopoéticas do "mundo-abrigo" que podem ser hoje reconfiguradas como mundo-escola do devir floresta anarquista dos sentidos para uma nova consciência grupal.

Neste texto, através da crença e confiança nos sentidos, Oiticica estava antecipando um futuro, ainda hoje urgente e emergente, como "um estágio evolutivo desses 'processos de atos vivos', podemos destacar a dissolução das antigas formas de arte, pintura, escultura etc., para o "objeto" híbrido" - eu chamo isso, nos meus trabalhos experimentais, um crecomportamento". (OITICICA, 1969)

O paralelismo entre os conceitos de inacabamentos existenciais do mundo e arte por fazer como "situação interrogante" de Souriau e a unidade tripartida - futurum, front, novum, das intenções antecipatórias de Bloch, propositivas do pensar e transpor cruza o texto de Oiticica pela perspectiva da dissolução do objetal para o comportamental como utopias negativas. Esta dimensão suprassensorial, crelazer e creprática já é em si prospectiva dos sentidos apontando para uma mudança inacabada, utopia não- 
ainda-concluída ou intenções antecipatórias ainda como dilema e desafios críticos, estéticos e éticos para o século XXI.

Paula Braga resgata de certa forma o que espelharia um pragmatismo utópico que para "a nova posição do artista é aquela que compreende que as estruturas criadas pelo artista crescem do mundo comportamental, depois de um longo processo de dissolução de 'atos do viver humano' $\rightarrow$ o destino dos atos do viver humano ocorrem sem esforços sublimatórios intermediários, conflitos transcendentais ou metas ideais." (OITICICA, 1986) Márcia Schuback alerta sobre a complexidade inquietante que paira sobre os desafios do mundo contemporâneo acerca "da dinâmica niilista que é a dinâmica de uma constante transformação, ou seja, de uma transformação que transforma continuamente todos os sentidos menos o sentido de transformação." E desta virada ou armadilha que se desgasta na dinâmica niilista na medida em que a transformação dos sentidos não "transforma o sentido de transformação". Tem-se daí o desafio da arte, da estética e da ética sobre a crença em uma virada pragmática utópica do papel da arte na transformação para os sentidos do comportamental. Ao mesmo tempo, a dis- solução da forma e do foco no objetal com os quais Oiticica apoiava suas visões e devires da arte assumem uma radicalidade tal como Márcia Schuback descreve como "mutação do sentido em todos os sentidos - é o século desafiado pela mutação das formas não só de pensar e viver, mas sobretudo da sensibilidade." Márcia Schuback complementa essa reflexão: "'O século XXI' como um 'século' [as aspas acentuam como hoje todos os sentidos estão comprometidos com a mutação de sentido] - que desafia o sentido de desafio enquanto oposição e acusação. É o 'século' - ou seja, a experiência de uma energia comum, uma energia que pode ser descrita como a de uma perda das formas".

O desafio abordado por Marcia Schuback não deixa de estar presente como "sintoma-intuição" expresso por Oiticica como dissolução das formas para as estruturas de comportamento. Em seu pragmatismo utópico, defendia a crença no "mundo-abrigo" da arte instaurando estruturas vivas para "auto-performance", "o papel do artista: propositor de condições para que o sujeito se torne o inventor de seu dia-a-dia; incitador de estados de invenção e do fim do objeto articuladas". Schuback, por sua vez,

Luiz Guilherme Vergara. Pós-fácil - O pragmatismo utópico do comportamental-grupal de Oiticica. 
coloca em questão o que Oiticica em sua época estava intuindo tanto em sua obra quanto na de Lygia Clark como evolução da arte para o crecomportamental. O que fica bastante coerente neste texto de Schuback é que esta dissolução da forma também alcança sua radicalidade no contemporâneo. "O grande desafio é descobrir a chance de outros sentidos, a chance de outras formas de pensamento e sensibilidade, com efeito, de pensamentos sensíveis e sensibilidades pensantes, dentro do risco da insensibilização crescente de uma racionalização instrumental, utilitária, calculadora, artificial de todos os âmbitos da vida e do viver."

\section{Parte IV}

Potência frágil dos sentidos de gerar futuros em gerúndio - Devir esboço - mundoescola-floresta

O "inacabamento existencial" pauta essa abordagem, ressaltando a aproximação do texto de Oiticica entre fenomenologia existencial de Merleau-Ponty e o pragmatismo (utópico) de William James atualizado pelas práticas anacrônicas dos sentidos. Hoje se coloca em dilema como potência frágil o retorno às questões apontadas pelo apareci- mento do suprassensorial (1967) e comportamental como proposições de ações e reviravoltas pelo coletivo. Enquanto o mundo hoje se torna um abrigo em risco, mais do que nunca se têm a atualidade de Etiénne Souriau ampliando a "obra por ser feita", em "esboço" (SOURIAU) para o "inacabamento existencial" tanto da arte quanto do humano. Ainda assim, são os sentidos do mundo que apontam a arte para sua urgência do agir diretamente como campo de pragmatismo utópico ou utopia negativa quando à dissolução formal, objetal, exige ações afirmativas do devir comportamentalgrupal.

Ressalte-se em especial o reconhecimento desta posição ética dupla das intenções e intuições de Oiticica como "sintomaintuição" (DUVE, 2005) ${ }^{14}$ antecipatórias da "necessidade vital" de envolvimento planetário de "diferentes modos de existência" ou "relações ocultas (da arte) com a vida prática... novas maneiras de viver. (PEDROSA, 1979, p. 145)

Na mesma medida em que se revive o "beco sem saída" da evolução humana, urge ainda mais a busca por novos contornos, viradas ou "cambalhotas" (termo de Mário 
Pedrosa), atualizando também o sentido de "comportamental" de Oiticica como construção de experiência, tendo o "pragmatismo" de John Dewey e William James ${ }^{15}$ (JAMES, 1987, p. 506) como método com base no seu significado grego de "ação", prática e prático. (JAMES, 1987, p. 506), assim como James traz de Charles Peirce a relação entre clareza dos pensamentos de um objeto e a concepção de seus efeitos a partir de sua prática - sensações e reações intrínsecas às concepções integrais deste objeto em ação. Projeta-se o mesmo pragmatismo de James e Dewey sobre a fenomenologia existencial das estruturas de comportamento de Oiticica propostas a partir de Merleau-Ponty, como sentidos de instauração da obra como ação por ser feita e sua crença na mudança direta na ordem relacional da sensibilidade, do afeto e da restauração da confiança interpessoal - como terapêuticas sociais antecipatórias de novas transformações ainda por serem feitas no mundo contemporâneo. Tal como Lapoujade cita James serve para Oiticica - "aquilo que realmente existe não são as coisas feitas, mas as coisas se fazendo"16.

Ao longo de todo o seu texto, Oiticica defende a dissolução do objetal como proposição ética da arte com base na ação e práticas sensoriais. O que equivale ao esforço filosófico de James para defender o pluralismo-empirismo como negação do absoluto. O pragmatismo de James é revisto como ação e prática na qual "a realidade se faz; a realidade está por fazer. É como houvesse uma exigência moral do devir: o mundo não se faz sem estar ao mesmo tempo por fazer". (LAPOUJADE, 2017, p. 14) Oiticica, em outras palavras, em outro contexto, aponta para os sentidos, ou natureza afetiva da forma de Pedrosa, reconfigurando a dimensão infinita ou pluralista, indeterminante da obra-programa como estruturante do acontecer interpessoal, comportamental e grupal da arte (por ser feita).

A leitura contemporânea deste texto de Oiticica incorpora o que Souriau chama de "complexidade inquietante" indissociável da metalinguagem da escrita-trajeto caminhando e penetrando um labirinto espiral de giros para o comportamental pela "dissolução da arte-objeto" (OITICICA, 1969). O que pode hoje uma re-virada para o pragmatismo utópico da arte enquanto situação-intuição-indagação dos seus próprios modos de ação e práticas do devir? Como o "inacabamento existencial", proposto por Souriau, espelha as dissoluções e

Luiz Guilherme Vergara. Pós-fácil - O pragmatismo utópico do comportamental-grupal de Oiticica. 
falências do antropoceno e capitaloceno? A própria leitura hoje de Oiticica de 1969 é atravessada pela "espessura (das incertezas e indagações) do presente ${ }^{\prime 17}$, diante dos golpes e retrocessos democráticos crescentes. Ao que se chamava então de fim das utopias modernas, desdobram-se as utopias negativas do acontecer da desmaterialização e mesmo desintegração das formas artísticas não apenas de conceitos esteticistas hegemônicos, antecipados por Mário Pedrosa como Arte Pós-moderna ou Arte Ambiental (PEDROSA, 1965 in OITICICA, 1986), mas também do inacabamento existencial, espiritual e social, mais ainda, do inacabamento humano-inumano.

Acrescente-se à gravidade deste projetotrajeto o sintoma-intuição de que as dissoluções do objetal da arte no mundo contemporâneo são também da realidade que está por ser feita ou em dissolução juntamente com o "inacabamento existencial" de Souriau. A crise se inscreve como "atos de intenções" (BLOCH, 2005) e intuições propositivas de Oiticica para as relações comportamentais do humano-inumano-grupal, do local, mundo agora sem abrigo que diz respeito à própria condição humana como situação interrogante. A própria falência do antropoceno / capitaloceno estava sendo exposta ou radicalmente denunciada pela dissolução ou desintegração do foco no objeto. Ao mesmo tempo, os sentidos de mudança eram projetados como modos de agir na crença de uma realidade a ser transformada, daí o pragmatismo utópico ser indissociável da confiança nos sentidos de ação com as urgências de novas transformações.

Através da cuidadosa leitura de Lapoujade em Existências mínimas (2017) transpiram-se complexidades inquietantes que trazem para o contemporâneo os desafios e dilemas que se colocam nos sentidos de dissolução da forma simultaneamente com a emergência ou urgência que subjaz os entrelaçamentos entre "outros diferentes modos de existência". A classificação de Souriau dos diferentes modos de existência atravessa categorias do humano-inumano por fenômenos, coisas, imaginários e dimensão virtual. $O$ ato criador seria então um movimento atravessador dessas modalidades pelo sentido transmodal. Um texto de 1969 não publicado até hoje (como é o caso do Oiticica, igualmente não traduzido do inglês para o português), tal como uma ponte não construída, é como um objeto inacabado no mundo colocado por Souriau na categoria de "virtual". Assim, também o lega- 
do de ideias e obras por serem feitas, o pragmatismo de James revisitado, sua releitura como utopia pragmática da ação se adere ao inacabamento existencial, tal como a categoria "virtual" proposta por Souriau. Entretanto, opta-se com Lapoujade a exaltação de Souriau, ao reler e traduzir The Senses Pointing Toward a New Transformation para o contemporâneo:

\section{Cada existência pode tornar-se uma incitação, uma} sugestão ou o germe de outra coisa, o fragmento de uma nova realidade futura. Toda existência torna-se legitimamente inacabada... Vemos agora que as existências podem se modificar, se transformar, intensificar sua realidade, passar de um modo para outro, conjugá-los. Entramos no domínio do transmodal. (LAPOUJADE, 2017, p. 39)

Assim, com este texto-trajeto de indagações e inquietações são percorridos alguns sentidos de devir esboço de mundo-escolafloresta que se inscrevem na escrita espiral de labirintos anarquistas de contínuas bifurcações triangulares entre delírios, desvios e desafios, que se colocam na tríade futurumfront-novum (Bloch) por um pragmatismo utópico da arte.

\section{Notas}

${ }^{1}$ Hélio Oiticica, The Senses Pointing Toward a New Transformation (Os sentidos apontam para uma nova transformação), 1969. Originalmente escrito em inglês para o "Touch Art", simpósio realizado no California State College, entre 7 e 12 de julho de 1969. Projeto Hélio Oiticica 0486/69, páginas datilografadas 1 a 6 . Acessível online: http://www.itaucultural.org.br/programaho/

2 Documentação do Projeto HO. PN15 - Série Newyorkaises. Título do projeto: Subterranean Tropicália Projects. Local de concepção: Nova York, 1971. Acessível online: http://www.itaucultural.org.br/programaho/

${ }^{3}$ Encontro acaso - barca Charitas de $9 \mathrm{~h}$. dia 07 novembro 2019. Melissa Oliveira (melissaomaciel@outlook.com) (21 anos). (KUNDERA, 2017)

${ }^{4}$ Termos usados por Hélio Oiticica em texto inédito $A c$ count sobre Devolver a terra à terra em KLEEMANIA a 18 de dezembro de 1979 no Caju. In PROJETO HÉLIO OITICICA. Catálogo Hélio Oiticica. Rio de Janeiro: Centro de Arte Hélio Oiticica, 1997, p. 202.

${ }^{5}$ Relatos de membros do grupo de estudos espirituais da Fundação Avatar. Grupo dissidente da Loja Rosa Cruz de Niterói liderado pelo Dr. Jaime Treiger. Zé Oiticica era conhecido como Mestre Oiticica com práticas de aula extremamente experimentais e inovadoras, segundo esses relatos.

${ }^{6}$ Tania Rivera, ao abordar as relações entre arte e psicanálise, usa o sentido de "cambalhota no cosmos" de Mário Pedrosa a partir de duas imagens que podem ser incorporadas como giros entre utopias em dissolução e distopias da arte no mundo contemporâneo - a banda de moebius e a "cambalhota no cosmos sobre si mesmo" proposta por Mário Pedrosa. (RIVERA, 2013, Introdução).

7 Juan Acha. "En tal sentido, su punto de partida implica un rechazo de lo que él denomi-na: eurocentrismos, articentrismos, monoesteticismos y bello-manías. Es decir, rechazo de toda estética que se construya desde 
categorías europeas exclusiva-mente (eurocentrismo), de toda reflexión que se centre en un único y excluyente concepto de arte o de belleza, generalmente occidental (articentrismo y be-llo-manía), o que pretenda la existencia de un exclusivo principio estético ( $\mathrm{mo}$ noesteticismo). In VICENTE, Sonia. Tiempos de diseño. Una vision de la teoria de los diseños desde la postura de Juan Acha. Módulo 1: Mendoza: Universidad y Sociedad, Facultad de Artes y Diseño, 2000. Ver também: ACHA, 1979.

${ }^{8}$ Resumo Série Conglomerado Subterranean Tropicália Projects. Texto enviado para Universidade de Buffalo, na qual Hélio Oiticica descreve seus projetos $P N 10$, $P N 11, P N 12, P N 13$, que formariam o conglomerado Subterranean Tropicália Projects. Este grande projeto havia sido pensado para o Central Park de Nova York. São penetráveis que preveem a possibilidade de performances. H. O. anuncia um terceiro projeto (o PN15). Junto com a descrição, menciona a inclusão de plantas, fotografias e maquetes. As performances não foram ainda explicitadas porque, segundo $\mathrm{H}$. O., dependem do local em que os projetos serão construídos. In Projeto dos Subterranean Tropicália Projects. http://54. 232.114.233/extranet/enciclopedia/ho/index.cfm

${ }^{9}$ Artigo neste dossiê: Os sentidos e a urgência de transformação.

${ }^{10}$ Vera Oiticica era tia de Hélio Oiticica e frequentou o centro de estudos e ciência espiritual da Fundação Avatar nos 1980 e 90 . Somente quando soube que eu havia entrado para a direção de Educação do MAC-Niterói em 1996 que Vera Oiticia veio compartilhar algumas memórias de seu sobrinho, Hélio Oiticica.

${ }^{11}$ Declaração para filme Ivan Cardoso, citada por Cesar Oiticica Filho em seu artigo neste dossiê.

12 Étienne Souriau (1892-1979) foi um filósofo francês "fora de moda", conforme apresentam Isabelle Stengers e Bruno Latour. Recentemente citado por Peter Pál Pelbart, que demonstrou especial interesse em seus conceitos de instauração e os diferentes modos de existência.
${ }^{13}$ Hélio Oiticica, 4 de setembro de 1960: "A meu ver, a quebra do retângulo do quadro ou de qualquer forma regular (triângulo, círculo etc.) é a vontade de dar uma dimensão ilimitada à obra, dimensão infinita". (OITICICA, 1986, p. 21)

14 “Um sintoma é um sinal. É preciso saber lê-lo. É um indício. E uma intuição é a mesma coisa, mas do lado do criador do sintoma." (DUVE, 2005, p. 6). In. Entrevista com Thierry de Duve, 2005. Disponível em: https://www.scribd.com/document/124935246/Entrevista-Thierry-de-Duve

15 JAMES, William. Pragmatism. In JAMES, William. The Varieties of Religious Experience. Pragmatism. A Pluralistic Universe. The Meaning of Truth. Some Problems of Philosophy. Essays. Boone, lowa: The Library of America, 1987, p. 506.

${ }^{16}$ Lapoujade cita William James em A Pluralistic Universe. (LAPOUJADE, 2017, p. 11)

${ }^{17}$ Oiticica se apropria mais uma vez das intuições de 


\section{Referências}

ACHA, Juan. Arte y sociedade: Latinoamérica. El sistema de producción. México: Fondo de Cultura Económica, 1979.

BLOCH, Ernst. O princípio esperança. Rio de Janeiro: Contraponto, Ed. UERJ, 2005.

BRAGA, Paula. Hélio Oiticica. Singularidade Multiciplicidade. São Paulo: Perspectiva, 2013.

CARRASCO, Fredy Parra; REBECO, Patricio Miranda. Pensamiento social de la Iglesia y ciencias sociales: horizontes teológicos para um diálogo. Anales de Facultad de Teologia, Caderno 2 (Santiago do Chile, Pontificia Universidad de Chile), v. LVII, 2006.

JAMES, William. Pragmatism. In JAMES, William. The Varieties of Religious Experience. Pragmatism. A Pluralistic Universe. The Meaning of Truth. Some Problems of Philosophy. Essays. Boone, Iowa: The Library of America, 1987.

KUNDERA, Milan. A insustentável leveza de ser. São Paulo: Schwarcz, 2017.

LAPOUJADE, David. William James, a construção da Experiência. São Paulo: n-1 edições, 2017.

PEDROSA, Mário Pedrosa. Arte Ambiental, Arte Pós-Moderna, Helio Oiticica [1965]. In OITICICA, Hélio. Aspiro ao grande labirinto (Organização: Luciano Figueiredo; Lygia Pa- pe; Waly Salomão). Rio de Janeiro: Editora Rocco, 1986.

PEDROSA, Mário. Especulações estéticas III: lance final. In AMARAL, Aracy. Mário Pedrosa: mundo, homem, arte em crise. São Paulo: Editora Perspectiva, 1986.

PEDROSA, Mário. Arte, forma e personalidade. São Paulo: Kairós, 1979.

PELBART, Peter Pál. Por uma arte de instaurar modos de existência que "não existem". In BIENAL DE SÃO PAULO. Catálogo da $31^{a}$ Bienal de São Paulo. Como viver com coisas que não existem. São Paulo: Fundação Bienal de São Paulo, 2014.

PONTY, Merleau. Fenomenologia da percepção. São Paulo: Martins Fontes, 1999.

PROJETO HÉLIO OITICICA. Catálogo Hélio Oiticica. Rio de Janeiro: Centro de Arte Hélio Oiticica, 1997.

RIVERA, Tania. Introdução. In RIVERA, Tania. $O$ avesso do imaginário: arte contemporânea e psicanálise. São Paulo: Cosac Naify, 2013.

SOURIAU, Etiénne. Del modo de existencia de la obra por hacer. Buenos Aires: Cactus, 2017.

Luiz Guilherme Vergara. Pós-fácil - O pragmatismo utópico do comportamental-grupal de Oiticica. 